Protestantismo em Revista é licenciada sob uma Licença Creative Commons.

http://dx.doi.org/10.22351/nepp.v44i1.3370

\title{
Espiritualidade no cotidiano: um olhar a partir do corpo masculino
}

\author{
Daily spirituality: \\ an approach analyzed towards to male's body
}

Darlei de Paula*

\begin{abstract}
Resumo
Este artigo visa apresentar reflexões teológicas baseadas em uma pesquisa que se pautou no auxílio de teorias antropológicas e teológicas. O método de pesquisa empregado foi o de revisão bibliográfica. A proposta de investigação passou a ser conduzida a partir da seguinte questão: Há uma espiritualidade no comportamento masculino laico expresso no dia-a-dia fora de qualquer espaço de culto? A espiritualidade cotidiana é um comportamento relacionado a fatores constitutivos antropológicos do indivíduo justificáveis pela via Teológica. Existe uma relação entre a apresentação do corpo do homem nos dias atuais com a espiritualidade. Nós mantivemos a preocupação em identificar e buscar através de critérios de avaliação o comportamento masculino e sua relação corporal estética com a espiritualidade. Acreditamos que há uma espiritualidade no comportamento codidiano masculino não tido como religioso institucional.
\end{abstract}

\section{Palavras-chave}

Corpo masculino. Teologia, Estética e espiritualidade do cotidiano. Religião vivida.

\begin{abstract}
This article aims to present theological reflections based on a research that was supported by anthropological and theological theories. The method used was the bibliographic review. The first question for the research proposal was emerged in such way: Is there spirituality on lay male behaviour expressed in everyday life outside any space of worship? Everyday spirituality is a behavior related to the anthropological factors of the individual justifiable by the Theological way. There is a relation between the presentation of the male's body in the present day with spirituality. We have kept the concern about identifying and searching through evaluation criteria the male's behavior and its aesthetic corporal
\end{abstract}

[Texto recebido em junho de 2018 e aceito em julho de 2018, com base na avaliação cega por pares/ realizada por pareceristas ad hoc]

* Estagiário de Pós-Doutorado em Teologia (Faculdades EST). Doutor em Teologia Prática (Faculdades EST). Mestre em Filosofia (PUCRS). Graduado em Filosofia (PUCRS). Professor de Metodologia da Pesquisa, Ética e Bioética na Graduação e Pós-Graduação (Faculdade SEG). Este artigo é parte da pesquisa de Estágio de Pós-Doutoramento na temática Espiritualidade e o Cotidiano sob supervisão do Prof. Dr. Júlio Cezar Adam, Coordenador da Pós-Graduação das Faculdades EST. E-mail: darleidepaula@gmail.com 
relation with the spirituality. We believe that there is a spirituality in everyday male's behavior not seen as an institutional religious adoption.

\section{Keywords}

Male body. Theology. Everyday aesthetics and spirituality. Lived Religion.

\section{Introdução}

O que significa ter saúde? Significa não estar doente. Além de manter hábitos saudáveis e cultivar a espiritualidade. ${ }^{1}$ A espiritualidade pode ser definida através de traços visíveis que identificamos no comportamento da pessoa, ou sua forma de conduzir a própria vida numa concepção ética condizente com a realidade que visa o bem estar de todos. Uma postura que pode remeter a uma interpretação sobre o comportamento da vida das pessoas, membros ou não, adeptos ou não de uma religião, ou até mesmo, semelhanças e características que apontam ao religare, isto é, a conexão com o sagrado, e que de certa forma apresentam muitas semelhanças com comportamentos de membros de uma religião institucionalizada. ${ }^{2}$

Utilizaremos o termo espiritualidade e não religiosidade em nosso texto, por ser uma palavra com conotação mais abrangente e não estar etimologicamente conotada com o termo religare. Assim, não corremos o risco de confundirmos a promoção da crença pessoal, da religião vivida (aqui subentendida como espiritualidade pessoal) que alguém possa desenvolver, cultivar através de um determinado comportamento ou postura, com a espiritualidade oriunda de uma instituição religiosa, isto é, grupo ou igreja. Assim, nós nos isentamos e evitamos correr o risco de um possível proselitismo institucional religioso, instituído em nossa sociedade contemporânea. Entretanto, nossa preocupação vincula-se a comportamentos do cotidiano que podem ser entendidos como uma prática de espiritualidade com um espectro de alcance amplo. ${ }^{3}$

Segundo Frankl, a espiritualidade pode ser inconsciente e é a fonte e raiz de toda espiritualidade consciente. Neste sentido, a espiritualidade do cotidiano pode conter elementos inconscientes que marcam as ações humanas do dia a dia. ${ }^{4}$

1 “Em 2003, a Organização Mundial da Saúde incorporou a espiritualidade na reflexão e definição de saúde (CNBB, CF2012)". DE PAULA, Darlei. Espiritualidade Terapêutica: critérios da Logoterapia aplicados na Lectio Divina para reabilitação de adictos. Tese (Doutorado em Teologia) - Programa de PósGraduação em Teologia, Faculdades EST, São Leopoldo, 2012. p. 28.

2 "La palabra religión solo quiere decir 'hacer conexiones' religare, pero el origen de nuestras creencias en conexiones más amplias que nuestra vida misma surge desde algunas experiencias fundamentales como el nacimiento y la sexualidad. El lenguaje religioso está ligado con las experiencias que vivimos". GEBARA, Ivone. Antropología Religiosa: Lenguaje y Mitos. Buenos Aires: CDD, 2002. p. 30.

3 Entendemos por espiritualidade "a experiência mística e o cotidiano devem estar perfeitamente integrados. São duas dimensões da autêntica espiritualidade". CONTE, Ildo. A vida do amor. Petrópolis: Vozes, 2001. p. 25.

4 FRANKL, Viktor. Logoterapia e análise existencial. São Paulo: Psy II, 1995. p. 79. 
Espiritualidade abrange todas as dimensões da existência. Espiritualidade é uma forma de situar-se dentro da realidade do mundo. Por isso compromete a totalidade da pessoa em tudo o que faz ou deixa de fazer, em suas relações consigo mesma, nas relações com as coisas e com as pessoas, com seu corpo, com sua alma, com sua mente, com sua vontade. ${ }^{5}$

A totalidade acima descrita no conceito de espiritualidade de Frankl pode passar pela compreensão veterotestamentária na qual encontramos preconizados em alguns textos, elementos que serviram para as pessoas, naquela época, se guiarem como código de postura, um deles, expresso no livro de Levítico no Antigo Testamento. Nesse livro, algumas práticas com marcas exteriores visíveis, são muito fáceis de serem identificadas, provavelmente uma forma entre os pares que formavam os primeiros grupos semitas. Algumas dessas exigências eram exigências para se ter um sinal de pertença ao grupo. Hoje os sinais são outros e dos mais variados, e nos mais variados grupos, como nos propomos a expor nesse texto. O que acreditamos sinalizar que há uma espiritualidade cotidiana existente nos comportamentos da atualidade.

\section{Espiritualidade e comportamento}

Como vimos logo acima, é correto afirmar que ter saúde também é sinônimo de qualidade de vida, e a qualidade de vida inclui a esfera da espiritualidade. Mas, uma pessoa que reproduz um comportamento, ou sinais externos semelhantes às práticas cristãs, nos permite classificar através de tais características serem pessoas detentoras de espiritualidade? Nosso propósito reside em mantermos o foco na espiritualidade do cotidiano. Portanto, nossas características devem expressar os sinais do cotidiano, mas quais são eles?

O conceito base que define as práticas cristãs está relacionado à análise de elementos, traços ou indícios implícitos ou explícitos nos textos bíblicos do Antigo Testamento no livro de Levítico e no Novo Testamento em Hebreus. Ao que se refere implícito podemos apresentar a partir de investigação sobre a perspectiva hermenêutica. ${ }^{6}$

O que nos propomos explicar reside em expor a seguinte premissa: Até mesmo quando em pessoas aparentemente inidentificáveis (pelo que classificamos em senso comum) em sua espiritualidade, seja através dos sinais externos ou características, ainda assim, há uma espiritualidade presente. E, essa espiritualidade se demonstra através dos comportamentos, posturas e ações do cotidiano que são heterogêneas e, portanto, podem

CONTE, 2001, p. 35.

6 "Hermenéutica és una interpretación basada en un previo conocimiento de los datos (históricos, filológicos, etc) de la realidad que se trata de comprender, pero que a la vez da sentido a los citados datos por medio de un proceso inevitablemente circular, muy típico de la comprensión en cuanto método peculiar de las ciencias del espíritu. La hermenéutica permite a un autor mejor de lo que él se comprendía a si mismo". FERRATER MORA, José. Diccionario de Filosofía abreviado. Buenos Aires: Sudamericana, 1970. p. 192.

Protestantismo em Revista | São Leopoldo | v. 44, n. 01 | p. 238-257 | jan./jun. 2018

Disponível em: <http:// periodicos.est.edu.br/index.php/nepp> 
ser identificadas como espiritualidade através de outras vias. Isso ocorre porque expressam atitudes, posturas e imagens as quais não são cognatas aos grupos e correntes contemporâneos compreendidos como segmento espiritual.

O comportamento, postura ou imagem que se revelam em crenças, ainda que pessoais podem contribuir para que as pessoas sintam-se bem e inseridas na sociedade, além de ajudar a mantê-las fora de um espectro de adoecimento. Isto ocorre porque entendemos que a espiritualidade é uma esfera da vida saudável inerente ao ser humano, e não requer a necessidade de professar alguma religião institucional. ${ }^{7}$ Em outras palavras, a espiritualidade do cotidiano independe das religiões e da escolha por uma crença oficial. Ela é parte da vida diária do ser humano. Em nosso foco de estudo acreditamos na tese de que existe uma espiritualidade cotidiana que se manifesta no cuidado com a estética do corpo masculino. Nossos esforços de pesquisa visam mostrar quais são esses traços e seus impactos na convivência social numa perspectiva do masculino, sem a preocupação em definirmos a orientação sexual do indivíduo.

Buscamos identificar e apontar critérios que contribuam nessa visualização da espiritualidade do cotidiano. Entendemos que investigar a espiritualidade cotidiana também está intimamente ligado com a compreensão antropológica que Rivière faz, por exemplo, numa analogia entre esporte e religião:

Podemos sem dúvida, inferir a existência de um elo inicial entre o esporte, a religião e a política das cidades ou impérios. A devoção dos gregos aos esportes inscreve-se na invenção e sacralização do estádio. Nos estádios de Delfos ou de Olímpia, a atividade física junta-se às convenções e à homenagem aos deuses tutelares. ${ }^{8}$

Apesar da analogia de Riviére limitar-se nesse trecho entre o esporte e religião, acreditamos que podemos empregar a mesma linha de raciocínio para espiritualidade e o cotidiano. Entendemos que a espiritualidade está imbricada em comportamentos e práticas simples desse cotidiano contemporâneo como a imagem pessoal que cada um expressa.

Essa analogia contribui para tomada de consciência daquilo que percebemos e sentimos salutar a nossa vida corriqueira integralmente, até mesmo porque, por exemplo, a imagem está relacionada à autoestima que por sua vez está relacionada à saúde mental da pessoa. Pois promove o corpo, a mente e o noológico. Conforme Xausa, “o espiritual

7 Em Os Ritos Profanos, Riviére faz uma analogia entre o esporte e a religião, em especial cita o futebol e comparações com a religião e seus comportamentos e ritos. Acredito que é uma forma ilustrativa de facilitar a relação existente entre a existência de uma religião institucional e outra que faz alusão à mesma e à necessidade em sentir-se identificado com os demais. RIVIÉRE, Claude. Os ritos profanos. Petrópolis: Vozes, 1997.

8 RIVIÉRE, 1997, p. 213. 
refere-se ao noos e pode ser chamado de noético; indo mais além do religioso". ${ }^{9}$ Exatamente nossa intenção: a espiritualidade.

A autotranscendência é uma capacidade que nos remete ao conceito de espiritualidade pela esfera noológica. $\mathrm{O}$ espiritual refere-se ao noos grego e pode ser chamado de noético. Mas o noético ou espiritual podemos encontrar numa dimensão superior humana. ${ }^{10}$

Alguns comportamentos e gestos oriundos ou não de crenças pessoais, por repetição ou adesão de determinados grupos, ou ainda, marcas visíveis podem sinalizar práticas ou traços dessa espiritualidade (ideia de pertença) ou uma espiritualidade (mais pessoal e abrangente) numa linguagem mais apropriada, quase uma espécie de segmento de espiritualidade popular velada. ${ }^{11}$ Segundo Chupungo, podemos também considerar como pertença pessoal de espiritualidade as práticas e comportamentos aos quais ultrapassam as instituições religiosas formais e seus cultos e preceitos perpetuando suas práticas, embora desconectados, muitas vezes, de sua origem. ${ }^{12}$

Então surge a questão: de onde provavelmente possam ter emergido tais considerações de que essas experiências ou práticas seriam saudáveis ao indivíduo? Essa é nossa pergunta inicial, cuja etimologia da questão não é possível esgotarmos nessa pesquisa.

Tal dúvida, por possuir um espectro de abrangência amplo, requer pesquisa em várias áreas do conhecimento das ciências humanas, e, mesmo assim, corre-se o risco de não se alcançar o êxito. Para tanto, em caráter de facilitar a escrita de um texto mais focado, mantivemos a linha de raciocínio definida em uma única categoria: espiritualidade cotidiana relacionada aos sinais contemporâneos na imagem do corpo do homem sob a análise de um olhar teológico e antropológico. ${ }^{13}$

Os textos bíblicos foram analisados a partir da Bíblia de Jerusalém, o referencial antropológico na obra de Claude Riviére “Os Ritos Profanos". Contudo, não desconsideramos outros autores como a Teóloga Ivone Gebara, o Teólogo Hildo Conte.

9 XAUSA, Izar A. de Moraes. O sentido dos sonhos na psicoterapia em V.F. São Paulo: Casa do Psicólogo, 2003. p. 127.

10 DE PAULA, 2012, p. 132.

11 Entendemos como religiosidade popular a "vivência da fé, aquilo que os adeptos de uma religião elaboram. O que os adeptos fazem com a sua religião é o que determina a sua atitude, o seu comportamento, a sua maneira de pensar". DROOGERS, André. Religiosidade Popular Luterana. São Leopoldo: Sinodal, 1984. p. 7.

12 É importante lembrar que no estudo das Ciências Litúrgicas encontramos na sua formação histórica menção de que o Ordo Romanus já apresentava traços da cultura romana secular. Entre esses, o temperamento da condução celebrativa na forma ritual com características funcional e um tanto linear. CHUPUNGO, Anscar J. Liturgias do futuro. São Paulo: Paulinas, 1992. p. 09.

13 Consideramos antropológico a linha da psicologia chamada Logoterapia, aqui representada pelos autores Viktor Frankl, Elisabeth Lukas e Izar Xausa. 
Entendemos que, muitas vezes, a representação simbólica de uma cultura específica expressa num grupo, ou que gera marcas representativas das crenças ou práticas religiosas de determinado grupo, pode contribuir nessa identificação. Conforme Riviére, as marcas exprimem uma confissão, um credo ou ainda, o fazer parte de uma comunidade superior, seja esta movida pela fé ou pelo culto dos antepassados ilustres com a possibilidade do surgimento de novos messias. Evoca a colocação em representação da excelência humana. ${ }^{14}$

Portanto, nosso estudo aponta para a primeira pista ao tentarmos solucionar o seguinte problema: Qual a contribuição, ou ainda, se há contribuição espiritual ${ }^{15}$ no comportamento masculino laico expresso no cotidiano fora de qualquer espaço de culto?

\section{Hipóteses a partir do comportamento social cotidiano}

Possivelmente, nossa herança histórica cristã contribua para a promoção e o cultivo, bem como para o reconhecimento da espiritualidade como integrante da vida humana de uma forma geral. Vivemos num país em que quase a sua totalidade populacional está de alguma maneira inserida em contextos cristãos ou professam a fé em alguma instituição religiosa dentro das mais diversas e distintas instituições cristãs. Não iremos considerar as várias denominações religiosas cristãs existentes no país.

Segundo Adam, "a revanche do religioso que vivemos é diferente de outros ressurgimentos que houve na história. O retorno do religioso na contemporaneidade é um fenômeno complexo, multifacetado. Uma de suas características é a independência da religião de suas respectivas instituições". ${ }^{16}$

Acreditamos ser pertinente sinalizarmos que historicamente tivemos a influência cristã em nosso código de direito, por exemplo, a influência de valores da ética cristã que permeia nossa sociedade nos apontando comportamentos desde os atos mais simples até os mais complexos. Citamos por exemplo o ato de infração em nossa legislação do ócio interpretado como vagabundagem e, portanto, contravenção penal ${ }^{17}$ e da prática do aborto

14 RIVIÉRE, 1997, p. 212.

15 Aqui entendemos por religiosa as influências e traços que estão relacionados por uma religião institucionalizada, podendo ser identificada a mesma pelos vestígios fenomenológicos analisáveis. E a espiritualidade a capacidade de autotranscendência que o indivíduo possui conforme está especificado logo acima no texto na abordagem do noos.

16 ADAM, Júlio C. Religião e culto em 3D: o filme Avatar como vivência religiosa e as implicações disso para a Teologia Prática. Estudos Teológicos, v. 50, n. 01, p. 102-115, jan./jun. 2010. p. 113.

17 No seu Art. 59, a lei considera vadiagem "entregar-se alguém habitualmente à ociosidade, sendo válido para o trabalho, sem ter renda que lhe assegure meios bastantes de subsistência, ou prover à própria subsistência mediante ocupação ilícita". Plenário aprovou nesta quarta-feira (08 de agosto de 2012) o Projeto de Lei 4668/04, do ex-deputado e atual ministro da Justiça, José Eduardo Cardozo, que retira da Lei de Contravenções Penais (Decreto-Lei 3.688/41) a punição para vadiagem. A matéria foi aprovada em votação simbólica e será enviada para análise do Senado. Disponível em: <http://www2.camara.leg.br/camaranoticias/noticias/DIREITO-E-JUSTICA/423736-CAMARAAPROVA-FIM-DA-PENA-DE-PRISAO-PARA-VADIAGEM.html>. Acesso em: 03 jun. 2018. 
como crime. ${ }^{18}$ Pois ser preguiçoso e atentar contra a vida ambos são pecados condenados inicialmente pela Igreja Católica Romana entendidos o primeiro como um dos pecados capitais (a preguiça) e o outro como atentar contra a vida humana. ${ }^{19}$

A espiritualidade cristã no Brasil é ainda a mais conhecida, e, provavelmente a que mais entra em contato direto coma população em geral influenciando comportamentos e atitudes, até então, não racionalmente explicáveis, mas compreensíveis, em primeira análise, algo simples que compõem nosso cotidiano. ${ }^{20}$

Baseado nas questões expostas no primeiro parágrafo desse texto, surgem as seguintes inquietações teológicas que transformamos em hipóteses de nossa pesquisa:

a) Valores nos traços ou características que contribuem para o desenvolvimento de um comportamento atualmente assumido pelos homens no cotidiano, em específico deixar o corpo liso sem pelos, ${ }^{21}$ ainda que muito comum entre as mulheres, permite os identificarmos como passíveis de uma prática popular, mas haveria relação com a espiritualidade? Esses sinais podem até passar despercebidos por muitos, em nosso contexto social e cristão. Não são facilmente identificáveis em sua origem. São sinais externos masculinos comuns em nossa sociedade. Qual a relação desses sinais que fazem parte do cotidiano com o cultivo do que consideramos comportamento relacionado à espiritualidade masculina?

b) Alguns comportamentos ou ações identificáveis no cotidiano por remetem ou apontam para uma conotação de práticas espirituais, ainda que sem a consciência de pertença religiosa, proporcionam melhora ou alívio do sofrimento psíquico e/ou noético segundo a crença pessoal? Tais práticas podem influenciar na vida comportamental do cotidiano masculino de forma a contribuir para uma vida saudável.

18 Em $1^{\circ}$ de janeiro de 1942 entrou em vigor o atual Código Penal Brasileiro, a teor do Decreto-Lei n. 2.848, de 7 de dezembro de 1942, Código esse alterado ao largo do tempo não só pontualmente mas incluso em toda sua parte genérica. Ao princípio de sua parte especial, o Código versou, em título relativo aos crimes contra a pessoa, os delitos contra a vida, entre eles o de aborto, considerado em cinco artigos: Arts. 124,-8. Disponível em: <http://www.providaanapolis.org.br/images/artigos/Ab_legal_VDH_Dip.pdf>. Acesso em: 03 jun. 2018.

19 Disponível em: http://www.vatican.va/archive/cathechism_po/index_new/p3s1cap1_1699_ 1876_po.html. Acesso em: 03 jun. 2018.

20 Segundo o IBGE, o número de cristãos no Brasil é de 86,8\% conforme censo de 2010. Disponível em: <https:/ / veja.abril.com.br/blog/reinaldo/o-ibge-e-a-religiao-cristaos-sao-86-8-do-brasil-catolicos-caempara-64-6-evangelicos-ja-sao-22-2/>. Acesso em: 30 abr. 2018. Em pesquisas mais recentes, o Datafolha registrou um percentual entre católicos e evangélicos em dezembro de 2016 um somatório de $79 \%$. Portanto, mesmo que haja uma tendência no aumento de pessoas sem religião, chegando a um percentual de 14\%, ainda há um grande número de cristãos. Disponível em: <http:/ / www.ihu.unisinos.br/eventos/564083-a-transicao-religiosa-em-ritmo-acelerado-no-brasil>. Acesso em: 30 abr. 2018.

21 Segundo Dougas Cruz, profissional da estética que concedeu entrevista ao site da Globo.com: “Muitos homens ficam sem camisa e a depilação valoriza a definição dos músculos. O homem que vai para a academia, malha, quer mostrar isso". Disponível em: <http://g1.globo.com/Carnaval2009/0,,MUL986678-16634,00-

HOMENS+SE+DEPILAM+PARA+VALORIZAR+OS+MUSCULOS+NA+AVENIDA.html>. Acesso em: 30 abr. 2018. 
c) Apontar critérios facilitará identificar o material para prováveis futuros estudos e pesquisas? Os critérios que provavelmente encontraremos contribuirão na seleção desses comportamentos e possivelmente serão a base para identificar outros comportamentos, ainda não divulgados em pesquisas, ou que ainda nem surgiram em nossa sociedade.

\section{Sinais corporais da estética do cotidiano}

Muitos são os sinais externos masculinos comuns em nossa sociedade atual, entre eles, deixar a barba crescer e dar forma ou modelagem das mais diversas, colorações aos pelos entre outras situações como as tatuagens e depilações. Abrimos inicialmente um parêntese para esclarecer que em pleno ano de 2018 vemos uma proliferação grande na abertura de barbearias espalhadas pelas cidades, tanto nas cidades de pequeno porte quanto nas grandes metrópoles. ${ }^{22}$

Basta lançarmos uma rápida busca pelos vídeos no YouTube, por exemplo, com o descritor "barba, barbearia, cuidado com a barba" e encontraremos vários profissionais e leigos falando e dando dicas do cuidado com a barba. ${ }^{23}$

Mas qual a relação da barba com a espiritualidade? Eis nossa questão. Não é um cuidado estético recente, e sim uma prática que já era adotada desde o AT, embora sem esses recursos atuais de divulgação sobre o tema, e com outros objetivos. Seria a barba uma relação do homem com a autotranscendência?

“(...) Não danificarás a extremidade da tua barba”. ${ }^{24}$ Essa era uma prática aconselhada no livro de Levítico e descrita como apropriada ao israelita. Isso também simbolizava principalmente o momento de luto que uma pessoa passava, entre outros sinais visíveis como a roupa, por exemplo, em outro trecho do Levítico (21.5) vemos que preservar a barba é uma conduta empregada dos sacerdotes.

Mas vamos nos ater à barba. Mais do que nunca, agora em meados do século XXI, pra ser mais preciso nos últimos cinco anos. ${ }^{25}$ Esse é um visual masculino muito comum.

22 Segundo um site especializado em administração de empresas, "nos últimos anos, observamos nos grandes centros o surgimento de barbearias à moda antiga. Tem cadeira com estofado de couro, decoração característica, navalha especial, shampoo com essência de cerveja, tônico de crescimento e uma lista de cosméticos e tratamentos de dar inveja a qualquer salão de beleza feminino". Mostrando que há um aquecimento no mercado em torno da barba. Disponível em: <http://www.administradores.com.br/noticias/cotidiano/consumidor-dita-as-tendencias-no-mercadode-beleza/124684/> Acesso em: 30 abr. 2018.

23 Pesquisa feita no YouTube no setor de busca com os seguintes descritores: barba: 2.500.000; barbearia: 146.000; cuidado com a barba: 19.600 resultados. Disponível em: <https://www.youtube.com/results?search_query=barbearia>. Acesso em: 30 abr. 2018.

24 Lv 19.28.

25 A reinvenção das barbearias se tornou um dos principais canais que estimulam o consumo de produtos de beleza entre homens. Em sintonia com o vigor de um mercado em ascensão, o Barber Week, evento realizado em meados de junho no Centro de Convenções Frei Caneca, em São Paulo, recebeu quase 4.900 visitantes interessados em aprender e empreender no ramo da barbearia. O evento, distribuído em uma 
Muitos homens têm tido o cuidado com a sua barba longa. Muitos as deixam grandes como sinal de pertença a um estilo, a uma fase da vida, a um grupo ou ainda, em sinal de expressão da masculinidade, sem esquecerem-se da vaidade no seu cuidado.

Embora reconheçamos que é uma marca de ordem do sexo masculino, não está relacionada à orientação sexual do homem, pois a orientação sexual independe das marcas e sinais externos. ${ }^{26}$ Por não ser uma pesquisa de identificação, classificação e reflexão sobre gênero e suas diferenciações, voltamos à temática da espiritualidade do homem de forma genérica.

Ainda hoje a Igreja Ortodoxa tem como costume a prática entre seus religiosos celibatários em não raspar a barba, o que facilita a identificação por parte dos leigos em reconhecer os irmãos monges ordenados ou não, e os padres ordenados casados aos quais são permitidos rasparem suas barbas e apararem os cabelos. Segundo as instruções da Igreja Ortodoxa Russa, a barba é parte integrante da imagem do padre. ${ }^{27}$

Os cabelos longos são sinal de nazir, o consagrado. Segundo o livro de Números (6.5). O nazierato é um período de consagração a Iahweh onde o consagrado entre outras observações não podia cortar o cabelo.

\section{Adornos}

Colocar adornos como piercing em várias partes do corpo, incluso órgãos genitais, fazer tatuagens e marcas que expressem uma admiração ou pertença a um determinado grupo social.

Num contexto histórico marcado por inseguranças, em que a crença em nossos próprios enunciados torna-se fragilizada, a prática das extremas marcações corporais se constituiria como recurso fundamental à construção de uma consistência autonarrativa. É como se as tatuagens funcionassem

área de $3.500 \mathrm{~m}^{2}$, trouxe cerca de 25 marcas, novidades para o setor e uma ampla grade de workshops com temáticas variadas sobre as inúmeras possibilidades do mercado profissional de barbearia. "Posso dizer com tranquilidade, já é o maior da América Latina voltado exclusivamente para o segmento de barbearia que vem crescendo vigorosamente ao longo dos últimos cinco anos". Disponível em: <https://abihpec.org.br/2017/07/pelas-barbas-do-profeta/>. Acesso em: 30 abr. 2018.

26 Orientação sexual significa, segundo o Dicionário Informal On line: Sexo pelo qual um indivíduo sente atração.

Disponível

em: $<$ https://www.dicionarioinformal.com.br/orienta $\% \mathrm{C} 3 \% \mathrm{~A} 7 \% \mathrm{C} 3 \% \mathrm{~A} 3 \mathrm{o} \% 20$ sexual/>. Acesso em: 07 maio 2018.

27 "4) The 16th rule for the priests of the Russian Orthodox Church Abroad says: 'A priest, who is fully supported by his parish, and is given the opportunity not to work at a secular job, should have the appearance of an Orthodox priest, that is, should have long hair, a beard, a riasa, wear a cross of a proper style, and not one he has thought of himself and in his external appearance fully exemplify a true pastor'". Disponível em: <http://orthodoxinfo.com/praxis/clergy_dress.aspx>. Acesso em: 30 abr. 2018. 
como uma espécie de diário, a salvo de qualquer risco de furto ou extravio. ${ }^{28}$

Há também proibições de certas marcas corporais, hoje disseminada como tatuagens. ${ }^{29}$ No livro de Levítico, vemos a recomendação de que não se faça tatuagem alguma. Ora, se essa era uma recomendação ao povo hebreu, então isso com certeza significava para época um costume oriundo dos povos pagãos. ${ }^{30}$ Logo essa recomendação iria dar forma a um comportamento de prática diferente aos israelitas, comum aos demais.

Reconhecemos em Levítico 19.28 que não devemos fazer nenhuma marca em nosso corpo até mesmo em razão de luto. Entende-se aqui que era uma prática dos pagãos da época fazerem marcas em seus corpos simbolizando o período de luto. Tanto quanto a marca está também a tonsura conforme vemos em Jr 16.6.

$\mathrm{Na}$ atualidade, as marcas, em outras palavras, tatuagens não simbolizam mais o luto, mas o sinal de pertença a uma determinada tribo. ${ }^{31}$ Principalmente quando tratamos de observar os jovens, por exemplo.

Embora sendo um sinal externo que, em princípio, não tem uma conotação com alguma crença, está carregado de sentido para quem adere a essa prática. Podemos afirmar segundo McGuire que necessitamos perceber que o ponto inicial deve ser entendido como conceitos inseridos a partir de uma construção social, em outras palavras, tanto a ideia de religião quanto de sagrado ou profano é uma construção. ${ }^{32}$

28 PINHEIRO, Marina; CARVALHO, Glória. Singularidade e mito: o corpo como potência subversiva. Revista Latinoamericana de Psicopatologia Fundamental, São Paulo, v. 20, n. 4, p. 728-748, dez. 2017. p. 733. Disponível em: <http://www.scielo.br/pdf/rlpf/v20n4/1415-4714-rlpf-20-04-0728.pdf>. Acesso em: 01 abr. 2018.

29 Na página do Brasil Escola do site UOL encontramos uma matéria que simplifica e exemplifica nossa escolha pela pesquisa no tema da tatuagem. Lá encontramos a seguinte colocação: "Algumas linhas azuis marcadas em seu corpo podem ser o mais antigo vestígio de tatuagem já encontrado ou cicatrizes de algum tratamento medicinal adotado pelos povos da Idade da Pedra. Já as múmias egípcias femininas, como a Amunet, que teria vivido entre 2160 e 1994 a.C. apresentam traços e pontos escritos na região do abdome, indicando assim que a tatuagem, no Egito Antigo, poderia ter relação com cultos à fertilidade. Além do uso em rituais, a tatuagem serviria também como identificação de grupos sociais, marcação de prisioneiros, ornamentação e até como camuflagem. Com o cristianismo a técnica caiu em desuso no Ocidente e foi proibida". Disponível em: <https://brasilescola.uol.com.br/curiosidades/tatuagem.htm> Acesso em: 30 abr. 2018.

30 Lv 20.28.

31 A ideia de tribo urbana, por exemplo, é comumente usada para descrever grupos de jovens que buscam se diferenciar tendo por base uma referência de grupo. Tal cultura inclui roupas, acessórios, músicas e gírias específicas para cada grupo. Filósofos, como Michel Maffesoli, e antropólogos, como José Guilherme Magnani, analisaram o fenômeno, que parece tomar uma importância crescente nos tempos atuais. Conte que as tribos que frequentam as grandes cidades contemporâneas (emos, punks, skinheads, rastafaris, hip-hoppers e tantas outras) geralmente associam-se a referências culturais cada vez mais globalizadas. Disponível em: <http://rede.novaescolaclube.org.br/planos-de-aula/cultura-juventude-eantropologia-urbana>. Acesso em: 03 jun. 2018.

32 McGUIRE, Meredit. Embodied Practices in Everyday Religion. New York: Oxford, 2007. p. 188. 
Logo, mesmo que digamos que uma marca não tenha sentido de ser entendida como um sinal religioso ou sagrado, ela possui uma relação que faz com que o indivíduo de uma maneira ou de outra se sinta parte desse grupo ainda que inconscientemente. Portanto, é no momento em que se torna parte de um determinado grupo que ocorre a possibilidade de sua ligação com o "corpo" do todo, ou seja, não deixa de ser uma maneira de o manter identificado, e porque não apontarmos para uma compreensão de uma identificação que passa ser parte de um comportamento da espiritualidade e pertença a um determinado jeito de ser? Nada nos impede de crermos nesse sinal (vínculo) de pertença.

\section{O corpo, traços e sinais: de limpeza, identidade ou estética?}

E o que dizer da prática dos frequentadores de academias, entre outros, a raspagem ou ainda, depilarem os pelos corporais. ${ }^{33}$ Há uma relação entre a promoção da saúde e esses sinais, ou ainda, quais são as possíveis relações com a espiritualidade? Conforme Suetti, "o lugar que o corpo torneado ocupa na relação de prioridades dos sujeitos é observado pelo modo como a população se organiza no seu cotidiano". ${ }^{34}$

Podemos começar nossa reflexão considerando que há uma identidade por detrás dessa ideia de corpo, e que meu corpo pertence a minha essência, embora haja a possibilidade de assumir os sinais corporais como resposta a uma transcendência que se resgata a partir da tomada de consciência corporal que não se esgota na presença física. ${ }^{35}$

Para tal constatação, entendemos que "a proteção do nosso meio ambiente inicia nas nossas quatro paredes e nossa proteção do mundo interior dentro da própria alma" . ${ }^{36}$ O reconhecimento do cuidado e prevenção de nossa saúde pode iniciar por práticas que influenciam o nosso comportamento e estilo de vida, no nosso caso em questão: a vida expressa em marcas ou sinais que remetem à compreensão de práticas espirituais a partir do visível, externo. Em outras palavras, não estaríamos totalmente desconectados do que entendemos por saúde também no que entendemos por espiritualidade.

\footnotetext{
33 A grande maioria do público masculino que vai atrás desses serviços especializados quer se livrar geralmente dos pelos das costas, ombros e peito. Já a virilha e parte íntima são o alvo preferido do público homossexual, embora muitas mulheres estejam levando seus maridos e namorados para dar um fim definitivo nos "arbustos embaixo da árvore" mirando mais higiene e prazer na relação sexual. Os esportistas, em especial corredores, nadadores e ciclistas, em busca dos milésimos de segundo a menos na classificação geral de seus esportes, depilam braços e pernas e alguns institutos tem até mesmo parceira com academias de ginástica. Segundo a esteticista Raimunda, mesmo alguns machos de plantão estão depilando as axilas, na vã esperança de suar menos ou deixar menos marcas na camisa. Disponível em: <https:/ / www.terra.com.br/vida-e-estilo/homem/comportamento/depilacao-e-a-nova-tendenciaentre-homens,7008c7ca1b137310VgnCLD100000bbcceb0aRCRD.html>. Acesso em: 30 abr. 2018.

34 SUEITTI, M. A. G.; SUEITTI, A. P. A corpolatria e os transtornos da imagem corporal: uma realidade que exige atenção e cuidado. Protestantismo em Revista, São Leopoldo, v. 37, p. 102-111, 2015.

35 CORREA, Velez Jaime. El hombre un Enigma. México: CELAM, 1995. p. 59.

36 LUKAS, Elisabeth. Prevenção psicológica. Petrópolis: Vozes, 1992. p. 39.
} 
Seria possível que algumas marcas visíveis em nosso tempo, nos corpos, sejam uma forma de expressar a espiritualidade, e dessa forma o bem-estar que cada um acredita promover independente da recomendação das instituições religiosas presentes na sociedade?

A pré-compreensão do corpo, como vemos em Lima Vaz, ajuda a esclarecermos nosso propósito de pesquisa:

O nível da reestruturação do espaço-tempo cultural do nosso estar-nomundo por meio do corpo próprio. Aqui se tem em vista o modelo corporal que é oregulador da Gestalt do corpo em determinada cultura ou tradição cultural. Portanto, no aqui e agora do espaço-tempo cultural estão presentes as técnicas de adestramento ou modelagem da figura corporal, como a ginástica, bem como as condutas interpessoais que se exprimem predominantemente através do corpo (...... ${ }^{37}$

Muitas pessoas entendem que o estilo de vida é responsável pelo bom funcionamento do organismo bem como, seu estado de adoecimento, dependendo da prática de vida adotada. A idealização de hábitos transformadores oriundos de práticas externas, crenças populares e seus sinais identificados entre muitos membros da sociedade contemporânea visam contribuir para o cultivo da espiritualidade em prol de uma vida melhor segundo seus adeptos.

"Para penetrar melhor no mistério dessa espiritualidade, é conveniente, senão necessário, determo-nos na compreensão bíblica da corporeidade". 38 No Antigo Testamento, no livro de Levítico, uma espécie de código de conduta para os primeiros judeus.

Por sermos corpo estamos no campo de pertença a uma realidade material. Como vemos em Lima Vaz, na citação logo acima, a modelagem de nossa exposição corporal nos permite estar-no-mundo, nos permite interagir socialmente também.

Essa realidade nos move para dentro de uma dinâmica de apresentação tanto identitária individual quanto social. Em Lima Vaz, a categoria da corporalidade define-se como termo do movimento dialético, no qual o corpo é suprassumido pelo sujeito nesse movimento dialético, em outras palavras, podemos considerar que esse movimento dialético se move na perspectiva da compreensão de mundo, da interação social, da espiritualidade e da vida material. ${ }^{39}$ Isso é, ultrapassa a categoria individual.

Mas, quais seriam esses sinais na atualidade mais presentes em nossa sociedade?

37 LIMA VAZ, Henrique. Antropologia Filosófica. São Paulo: Loyola, 1991. p. 178.

38 ROY, Ana. Tu me deste um corpo. São Paulo: Paulinas, 2002. p. 27.

39 LIMA VAZ, 1991, p. 181. 


\section{Apresentação do corpo e relação com a espiritualidade}

Numa perspectiva teológica, essa prática nem sempre foi tida como uma forma de prazer e satisfação para divulgação do corpo. Basta darmos uma investigada em Levítico no AT ou Hebreus no NT e iremos descobrir seu emprego em circunstâncias muito distintas. Quais seriam essas? Vejamos sua empregabilidade.

Em se tratando da presença do corpo, isto é, de uma realidade material, bem como nos referimos logo acima. Na carta aos Hebreus, encontramos a seguinte expressão: “Tu não quiseste sacrifício e oferenda. Tu, porém, formaste-me um corpo (...). Por isso eu digo: Eis me aqui (...) eu vim ó Deus, para fazer tua vontade". .40

Esse trecho bíblico que se refere ao corpo, que marca a visibilidade, em presença, nem sempre foi compreendido dessa maneira clara numa tentativa até mesmo em expô-lo em público. Por exemplo, na idade média a sua compreensão vai por outra via de interpretação, na qual sua negação e práticas de mortificação e flagelo ganham lugar com a vergonha em escondê-lo e ainda castigá-lo como forma de se redimir dos pecados presentes no mundo. O corpo (a carne) paga pelo pecado.

A espiritualidade ocidental sempre foi tentada pelo dualismo. Muitas vezes o material era oposto ao espiritual. $\mathrm{O}$ corpo oposto à alma. (...) $\mathrm{O}$ belo, assim, ficou confinado a poucas ocasiões legítimas, como o oculto. Enquanto fora do momento sagrado a beleza era tratada com distância (se escondia o corpo com longas batinas pretas, e a ascese era exercitada com jejuns e cilício), no culto a beleza podia aparecer com brilho: objetos de ouro e artisticamente produzidos (...). O corpo a matéria, consagrados, serviam o louvor a Deus espírito-puro. Um fenômeno bem próprio do dualismo espiritual: de um lado o bem o ético, do outro o belo, o estético. ${ }^{41}$

Contudo, o dar-se conta do corpo e seu cuidado ou expressão para o sagrado nem sempre teve essa interpretação. Interessante notarmos que no AT no livro de Números a prática de raspar o corpo, que podemos interpretar como depilar, tinha outro sentido que não o de beleza, que entendemos como estética, mas de uma compreensão espiritual: “(...) raparão eles todo seu corpo $(. . .)^{\prime \prime} .^{42}$ Essa prática era tida como uma forma de purificação dos levitas para que assim, os tirassem todas marcas do profano.

Não entraremos no debate entre o que considerar sagrado ou profano por ser uma temática muito ampla que exigiria outra forma de pesquisa específica e novos focos de esclarecimento. 43

$40 \mathrm{Hb}$ 10. 5-7.

41 MAÇANEIRO, Marcial. Mística e erótica. Petrópolis: Vozes, 1995. p. 43-44.

42 Num 8.7.

43 Para Júlio Adam, “outra característica é a manifestação do religioso na esfera dita 'profana', ou seja, fora da instituição religiosa, fora da igreja instituição, fora da própria esfera religiosa. Mais do que 
Mas apenas empregamos esses dois termos como elementos opositores entre o que deve ser considerado adequado a uma vida de pertença, numa crença, relativo ao sagrado e, portanto, preparado para fazer parte desse corpo sagrado, ou aquele que necessita de uma purificação para ser digno de pertencer ao que é considerado como corpo sagrado. Entende-se aqui corpo sagrado a comunidade com uma identidade espiritual, a comunhão entre seus membros.

Embora não possamos esquecer que tanto a ideia de profano, quanto sagrado, foram se transformando à medida que a sociedade também se transformava na história. Essas mudanças de alguma forma contribuíram para o que hoje entendemos como uma visão de institucionalização das religiões.

Em outras palavras, facilitaram para que os membros da sociedade pudessem se identificar, se entender, se perceber como partícipes e, portanto, ainda que externamente, escolher ter a adesão às suas crenças. Dessa forma, geram a identidade de pertença a um determinado grupo espiritual a partir da observação de regras mais uniformes e claras, as quais apresentariam traços externos mais definidos de tal pertença, ora entendidos por puros, portanto pertencentes ao sagrado.

Afirma McGuire que essas marcas eram práticas importantes, pois seria através delas que se estabeleceriam as garantias da relação existente entre as pessoas e seus vínculos a partir de um mundo real em vista de um espiritual, garantindo assim a satisfação de suas necessidades como: cura, fertilidade, proteção ou ainda, contra a má sorte. ${ }^{44}$

Muito comum nos dias de hoje e ligado também à ideia de beleza, de estética estão as práticas de depilação, tanto femininas quanto masculinas.

No universo masculino, encontramos um nicho específico: a academia. Muitos homens que praticam exercícios em academias, de certa forma, entre outros objetivos, está o de facilitar a prática dos exercícios nos aparelhos a partir de um corpo liso, ou ainda, promover a sua apresentação da escultura corporal, percebendo visualmente o progresso de seu desenvolvimento muscular. Para isso, muitos utilizam-se da depilação tornando os músculos e o corpo como um todo mais visível.

Embora saibamos desse viés, não é difícil perceber que em "nossa sociedade de consumo se banaliza a beleza em função do lucro. A beleza natural substituída pelo plástico; a beleza erótica tornou-se pornografia" ${ }^{45}$

\footnotetext{
sincretismo, mais que transgressão de fronteiras, diluem-se as próprias fronteiras entre sagrado e profano". ADAM, 2010, p. 104.

44 McGUIRE, 2007, p. 189.

45 CONTE, 2001, p. 175.
} 
Segundo Conte, a espiritualidade é essencialmente erótica. Eros é impulso para unidade com tudo o que é belo, bom, alegre e verdadeiro. Para o autor, contemplar é buscar a verdade do ser que é amor e, portanto, a espiritualidade é necessariamente erótica. ${ }^{46}$

Poderíamos entender essa prática de depilação na atualidade como uma forma de ir além da promoção da aparência do corpo, uma forma de espiritualidade erótica? ${ }^{47}$ Seria esse comportamento uma marca corporal que expresse além da boa forma sua ligação com a pertença a um determinado grupo que compartilha os mesmos valores e promovam o seu próprio bem-estar e a autoestima unido-o a uma espiritualidade?

As fronteiras que marcam o comportamento ou sinais que identificam a pertença a uma forma de espiritualidade nem sempre são muito claras, apesar de suas práticas o serem, isto é, muitos ritos simbolizam externamente a incorporação de hábitos e de experiências tais como as expressões de fé que os identificam externamente.

Contudo, em certas situações ficam no campo externo, pois não há como medir a crença interna apenas na aparência. É verídica a afirmativa inversa. Percebamos que a partir desse ponto estamos substituindo definitivamente a palavra pertença a uma espiritualidade e, ou, grupo religioso marcado por uma espiritualidade identitária. Por entendermos que essa é muito mais abrangente e não necessita de barreiras que a mantenham aprisionadas a conceitos unívocos.

Segundo McGuire, práticas corporais são metáforas da realidade, seja ela considerada de cunho espiritual ou não, ainda que de promoção de uma espiritualidade intrínseca. Isto é, uma forma de capturar a essência em si da qual determinada prática o é. ${ }^{48}$

Ainda não temos uma resposta exata, nem é nosso propósito de investigação esgotar a temática com constructos definitivos, pois compete ao nosso objetivo lançar as chamadas hipóteses de reflexão, dar visibilidade a questão do corpo como sinal de uma espiritualidade e, portanto, sua pertença. Reconhecer que há uma espiritualidade no cotidiano do comportamento masculino.

Não podemos negar que seria uma possível futura linha de investigação a ser tratada em distintas pesquisas que validaria tal pertença e seus valores mais em específicos a crenças pessoais em conjunto com a ideia de coesão grupal.

Contudo, é correto afirmarmos que a partir de uma visão teológica cristã, ou ainda de um estudo exegético simples, não nos é difícil identificarmos e entendermos que no AT

46 CONTE, 2001, p. 175.

47 Para Conte, entende-se o Eros como o deus interior que impulsiona para transcendência, tanto para cima como para baixo. O impulso não é determinante, não é instintivo, mas é o espaço onde a pessoa exerce sua liberdade. CONTE, 2001, p. 143.

48 McGUIRE, 2007, p. 194. 
os levitas utilizavam dessa prática, por exemplo, de raspagem para poderem ser considerados purificados. Isto é, a raspagem os tornava puros pertencentes ao que consideramos corpo sagrado, em comunhão com o coletivo na espiritualidade.

E nos dias atuais? Seria a raspagem uma forma de ligar o corpo a essa ideia de limpeza e de pureza além da aparência? Por que não? Roy nos apresenta a ideia de que aceitar o seu corpo e o do outro é uma condição de crescimento do ser humano e também de sua espiritualidade. ${ }^{49}$ Ora, mais uma vez corpo e espiritualidade se entrelaçam e não há como negar o erotismo como uma força vital partícipe dessa relação.

Isto quer dizer que a espiritualidade passa pelo corpo. Surge-nos outra questão: a limpeza externa dos pelos simbolizaria o propósito interno de ser puro? Poderia ser afirmativo e assertivo tal comportamento? Acreditamos e afirmamos que sim.

O que entendemos é que na atualidade o fenômeno expresso no estético corporal é fator de coesão grupal, ainda que entre membros de academias distintas, e com espiritualidades pessoais das mais diversas, ou autoidentificados como pessoas sem objetivo espiritual definido ou ainda, crença pessoal clara e definida.

Então nos resta apelarmos para reflexão da antropologia sobre o corpo, ainda que de linha reflexiva que nos remete a filosofia aristotélica:

Tão nocivo é olhar o corpo como um espiritualismo exagerado, que o considera removedor, cárcere e obstáculo para a vida nobre ou espiritual, como olhá-lo como um materialismo extremo e extremo e excludente que somente considera real o sensível ou empiricamente observável. Nossa tese evita os dois extremos dizendo que o corporal é organismo natural, fisicamente real mas que implica transcendência, quer dizer, que não se reduz a mera coisa senão que inclui relações humanas. ${ }^{50}$

Embora tenhamos muitas denominações cristãs que mostram um comportamento dos seus seguidores através de regras rígidas de conduta no que se refere à exposição do corpo, muitas vezes numa tentativa de negação da condição humana através da interpretação de pecado e impureza por ter um corpo esteticamente que poderia se sobressair ao espírito em atração, isto é, em relação a uma negação da naturalidade da composição do eros na vida humana.

Por outro lado, também temos os extremos em que o que menos importa são as regras morais que possam tolher a ideia de prazer e beleza estética corporal. Provavelmente uma contra-resposta ao comportamento anterior. Todavia, surge a necessidade e possibilidade de promovermos o equilíbrio considerando a integralidade do indivíduo em física, psíquica e noológica. E dessa forma reconhecemos afirmativamente

49 ROY, Ana. Tu me deste um corpo. São Paulo: Paulinas, 2002. p. 96.

50 CORREA, 1995, p. 56 [tradução própria]. 
que há uma espiritualidade cotidiana presente no comportamento masculino da atualidade.

\section{Considerações finais}

Iniciamos com a preocupação em identificar se há a relação entre a espiritualidade e o comportamento cotidiano. Tentamos apresentar uma compreensão de espiritualidade expressa em atos simples do cotidiano. Buscamos refletir sobre a influência de atos ainda que não conscientes possivelmente ligados a práticas ou costumes religiosos fora de um contexto institucional. Apontamos alguns exemplos que nos levariam a uma margem de análise, os quais possibilitam identificarmos grupos ou pessoas com práticas numa forma de espiritualidade fora do contexto religioso institucional.

Baseados em situações simples e aparentemente comuns entre nossa população masculina, exemplificamos alguns indícios que podem nos dar a ideia clara de valores de identificação em características de comportamentos, atualmente, assumido pelos homens no cotidiano. Um deles em específico, deixar o corpo liso (depilado), ainda que seja muito comum entre as mulheres, no público masculino tem ganhado espaço.

Esse traço visível nos permite identificar, por exemplo, um grupo, ainda que não reunido em um único espaço e com um único objetivo, como é o caso dos cultos religiosos, ou práticas de crenças populares, e que ainda se tratando de análise de uma questão estética masculina pode os identificar os homens que compõem esse mesmo nicho. Mas haveria relação com a espiritualidade? Sim, mas a resposta dessa pergunta não está exatamente na aparência, mas na crença pessoal de cada um em cuidar do corpo e sentirse parte de um determinado grupo que cultiva a saúde física através de exercícios físicos, cuidados estéticos ou simples ato de higiene corporal, ainda que inconscientes.

Esses sinais podem até passarem despercebidos por muitos, em nosso contexto social e cristão. Em primeiro momento, não são facilmente identificáveis entre a relação em sua origem com a espiritualidade.

Se considerarmos que práticas espirituais, ainda que sem a consciência de pertença a grupo religioso, proporcionam melhora ou alívio do sofrimento psíquico e/ou noético segundo a crença pessoal de cada um, porque não considerar, ou ainda, reconhecer que são integrantes da autoestima (parte da saúde mental) o cuidado do corpo e sua imagem e, portanto, promoção da saúde e da espiritualidade.

Acreditamos que tais práticas podem sim, influenciar na vida comportamental saudável das pessoas e de certa forma relacionam o comportamento atual com a ideia de que no passado essas práticas eram consideradas pertinentes a comportamentos religiosos. Podemos afirmar, portanto que há uma espiritualidade decorrente dessas práticas comuns 
que regem o cotidiano dos homens. Como no caso do início do artigo em que analisamos o ato de se depilar.

Em nosso enfoque, embora encontrássemos outros sinais como, tatuagem, cabelos e barbas longas, nossa preocupação foi em apresentar uma espiritualidade do cotidiano relacionada com esses atos simples de identificação com a imagem do corpo masculino. Pois tais atos de transformar em imagem pública um segmento específico conforme as características analisadas os unem pelo que entendemos como espiritualidade do cotidiano.

Outro ponto importante que tentamos explicitar no texto se refere a apontar critérios que visariam facilitar a identificação dos elementos que envolvem as práticas espirituais inconscientes em prováveis futuros estudos e pesquisas.

Em outras palavras, os critérios que provavelmente facilitariam encontrarmos uma nova seleção desses comportamentos e possivelmente seria a base para os identificar em novas situações, ainda não divulgados em pesquisas, ou que nem aparentemente surgiram nesse momento em nossa sociedade, iremos tratar em um próximo momento oportuno, contudo fica registrado as três bases:

a) Relação estética e valor ético: Ao analisarmos um comportamento estético, a busca de valores intrínsecos em tais práticas pode ser comparada? E, em especial na sociedade atual?

b) Imagem histórica e atual: A relação entre a imagem histórica e atual do corpo foi alterada, ou manteve os aspectos principais originais considerando os traços básicos da imagem percebida?

c) Crenças, culto e espiritualidade relacionada com a vida cotidiana: Os grupos ou pessoas que se utilizavam de tais práticas eram semelhantes em seus valores de vida e práticas cúlticas?

\section{Referências}

A BÍBLIA DE JERUSALÉM. São Paulo: Paulus, 2015.

ADAM, Júlio C. Religião e culto em 3D: o filme Avatar como vivência religiosa e as implicações disso para a Teologia Prática. Estudos Teológicos, v. 50, n. 01, p. 102-115, jan./jun. 2010.

BARBER Weck. Disponível em: <https://abihpec.org.br/2017/07/ pelas-barbas-doprofeta/>. Acesso em: 30 abr. 2018.

BRASIL Escola. Disponível em:

<https://brasilescola.uol.com.br/curiosidades/tatuagem.htm> Acesso em: 30 abr. 2018. 
BRASIL. Câmara dos Deputados. Disponível em:

<http://www2.camara.leg.br/camaranoticias/noticias/DIREITO-E-JUSTICA/423736-

CAMARA-APROVA-FIM-DA-PENA-DE-PRISAO-PARA-VADIAGEM.html>. Acesso em: 03 jun. 2018.

CHUPUNGO, Anscar J. Liturgias do futuro. São Paulo: Paulinas, 1992.

CONTE, Ildo. A vida do amor. Petrópolis: Vozes, 2001.

CORREA, Velez Jaime. El hombre un Enigma. México: CELAM, 1995.

CRUZ, Douglas. Disponível em: <http:/ /g1.globo.com/Carnaval2009/0,MUL986678$16634,00-$

HOMENS+SE+DEPILAM+PARA+VALORIZAR+OS+MUSCULOS+NA+AVENIDA.html >. Acesso em: 30 abr. 2018.

DE PAULA, Darlei. Espiritualidade Terapêutica: critérios da Logoterapia aplicados na Lectio Divina para reabilitação de adictos. Tese (Doutorado em Teologia) - Programa de PósGraduação em Teologia, Faculdades EST, São Leopoldo, 2012.

DICIONÁRIO Informal. Disponível em:

<https:/ / www.dicionarioinformal.com.br/orienta \%C3\%A7\%C3\%A3o\%20sexual/>. Acesso em: 07 maio 2018.

DINO (Empresa). Disponível em: <https://www.terra.com.br/vida-eestilo/homem/comportamento/depilacao-e-a-nova-tendencia-entrehomens,7008c7ca1b137310VgnCLD100000bbcceb0aRCRD.html>. Acesso em: 30 abr. 2018.

DROOGERS, André. Religiosidade Popular Luterana. São Leopoldo: Sinodal, 1984.

FERRATER MORA, José. Diccionario de Filosofía abreviado. Buenos Aires: Sudamericana, 1970.

FRANKL, Viktor. Logoterapia e análise existencial. São Paulo: Psy II, 1995.

GEBARA, Ivone. Antropología Religiosa: Lenguaje y Mitos. Buenos Aires: CDD, 2002.

LIMA VAZ, Henrique. Antropologia Filosófica. São Paulo: Loyola, 1991.

LUKAS, Elisabeth. Prevenção psicológica. Petrópolis: Vozes, 1992.

MAÇANEIRO, Marcial. Mística e erótica. Petrópolis: Vozes, 1995.

McGUIRE, Meredit. Embodied Practices in Everyday Religion. New York: Oxford, 2007.

MONTEIRO, Marko. Disponível em: <http:/ / rede.novaescolaclube.org.br/planos-deaula/cultura-juventude-e-antropologia-urbana>. Acesso em: 03 jun. 2018.

PINHEIRO, Marina; CARVALHO, Glória. Singularidade e mito: o corpo como potência subversiva. Revista Latinoamericana de Psicopatologia Fundamental, São Paulo, v. 20, n. 4, p. 
728-748, dez. 2017. Disponível em: <http:/ /www.scielo.br/pdf/rlpf/v20n4/1415-4714rlpf-20-04-0728.pdf>. Acesso em: 01 abr. 2018.

REVISTA Veja. Disponível em: <https://veja.abril.com.br/blog/reinaldo/o-ibge-e-areligiao-cristaos-sao-86-8-do-brasil-catolicos-caem-para-64-6-evangelicos-ja-sao-22-2/>. Acesso em: 30 abr. 2018.

RIVIÉRE, Claude. Os ritos profanos. Petrópolis: Vozes, 1997.

ROY, Ana. Tu me deste um corpo. São Paulo: Paulinas, 2002.

RUSSIAN Orthodox Church. Disponível em:

<http://orthodoxinfo.com/praxis/clergy_dress.aspx>. Acesso em: 30 abr. 2018.

SITE Administradores. Disponível em:

<http:/ / www.administradores.com.br/noticias/cotidiano/consumidor-dita-astendencias-no-mercado-de-beleza/124684/>. Acesso em: 30 abr. 2018.

SUEITTI, M. A. G.; SUEITTI, A. P. A corpolatria e os transtornos da imagem corporal: uma realidade que exige atenção e cuidado. Protestantismo em Revista, São Leopoldo, v. 37, p. 102-111, 2015.

UNISINOS. Revista do IHU. Disponível em:

<http://www.ihu.unisinos.br/eventos/564083-a-transicao-religiosa-em-ritmo-aceleradono-brasil>. Acesso em: 30 abr. 2018.

VATICANO. Disponível em:

<http://www.vatican.va/archive/cathechism_po/index_new/p3s1cap1_16991876_po.html>. Acesso em: 03 jun. 2018.

XAUSA, Izar A. de Moraes. O sentido dos sonhos na psicoterapia em V.F. São Paulo: Casa do Psicólogo, 2003.

YOUTUBE. Acesso em: <https://www.youtube.com/results?search_query=barbearia>. Disponível em: 30 abr. 2018. 